\title{
AN EMPIRICAL STUDY ON GUI-II INTERVIEW METHODS IN PARTICIPATORY DESIGN
}

\author{
Arsineh Boodaghian Asl ${ }^{1}$ and Michel Gokan Khan ${ }^{2}$ \\ ${ }^{1}$ Karlstad Business School, Department of Information Systems, Karlstad University, Karlstad, Sweden \\ ${ }^{2}$ Department of Mathematics and Computer Science, Karlstad University, Karlstad, Sweden
}

\begin{abstract}
Graphical user interface interaction interview (GUI-ii), is a recently purposed method in which designers can remotely co-design and review GUI prototypes by eliminating the need for physical presence of co-designers. However, there are some concerns regarding the accuracy of such remote interview methods, as users do not have any physical interaction with the designers during their interview. In this work, for the first time, we compare GUI-ii methods with the traditional face-to-face interview processes to study their effectiveness in various design phases. The result shows that GUI-ii method is most effective when used in Ozlab.
\end{abstract}

\section{KEYWORDS}

Human-Computer Interaction, Participatory Design, Interview Methods, Graphical User Interface, Prototype

\section{INTRODUCTION}

One of the critical aspects of designing interfaces is to find out what are the most vital end-users' needs. There are multiple cases where it is essential to gather information from the end-user during the designing process. To obtain information from the end-users, as co-designers in a co-design environment, designers combine participatory design techniques (Simonsen and Robertson, 2013; Spinuzzi, 2005) with interview methods.

There are different interview methods, one of the basic ones is the traditional face-to-face interview, where the designer meets the co-designer face-to-face, and they use paper and pencil to interview and gather information according to the design phase prerequisites. There are other interview methods developed such as think-aloud (Nielsen et al., 2002), post-task, and survey-based (E. Baauw et al., 2004) interviews.

GUI interaction interviews (GUI-ii) (Pettersson et al., 2017) is a new interview method where interviewees are creating user interfaces and interacts with them. It is interesting to evaluate its benefits under different conditions, to find out its limits, advantages, and disadvantages. There are various approaches for using the GUI-ii interview method, such as face-to-face interview, interviewing via screen-sharing and interviewing using the Ozlab web application (Pettersson and Siponen, 2002) which provides Wizard-of-Oz (Steinfeld et al., 2009) functionalities to enhance the interactive experience (Pettersson et al., 2018, 2017).

Majority of designers go through different interview methods to get the necessary information from the users according to their needs. Whether it's remote, face-to-face or even a combination of methods and approaches.

In this research, for the first time, we compare these GUI-ii approaches with traditional face-to-face interview method and analyze the benefits in each design phase according to different parameters, which will be covered later in the research method section.

\section{RELATED WORKS}

There are researches who did an empirical study on interview methods which are different from the ones covered in this work. The comparison they conclude was whether before starting the design, in information gathering phase, or after it, in the usability test phase. However, none of them covered the importance of choosing a suitable interview method in a co-design environment, especially from the human-computer interaction $(\mathrm{HCI})$ perspective. 
Dimond et al. (Dimond et al., 2012) did a comparison test on instant messaging, e-mail and phone, in order to find out that different methods have different effects on the test's result; they had used the following parameter for analyzing the result, first word count and second the quality code. They did not take the difficulty level into consideration that can affect the willingness to provide information, and thus on the quality of the test. In this work, we will discuss the willingness to provide information and represent its impacts through graphs.

Baauw et al. (Baauw and Markopoulous, 2004) results showed that girls tend to communicate more while they were encountering problems during the usability test than boys. However, all the children in this research were tested for usability testing, and they weren't involved as co-designers.

Brush et al. (Brush et al., 2004) also did a similar comparison. They listed five different issues of usability testing and they also did a survey on users who participated to remote and local tests and asked about their difficulties during the test, and they also recorded their voices and shared screens interactions during the interview. Even though the tools and techniques of their tests are very useful. The test was concentrated on the usability test and not participatory design.

On another empirical study by Johnathan Gratch et.al. (Gratch et al., 2014), four different interview methods such as face-to-face, teleconference, Wizard-of-Oz, and automated character (Ellie, a virtual animated character) has been compared. At the first two interview methods, the conductor was a human being, on the third and fourth interview methods the interviewer was Ellie. However, the goal of the research was not related to the participatory design field and not even to usability testing and it focused on supporting psychological conditions.

GUI-ii method has been developed by Pettersson, Wik and Andersson. in a research study called "Wizards of $\mathrm{Oz}$ in the Evolving Map of Design Research" (Pettersson et al., 2018, 2017).

\section{RESEARCH METHODOLOGY}

This research study has used qualitative methodology the main goal is to precisely explain and clarify the efficiency and quality of four different interview methods over one another.

\subsection{Interview Methods}

This research study will cover the comparison of the following four interview methods:

GUI-ii Face-to-Face: In this method, a designer, who is also the test leader, and a co-designer, who is called co-designer, will work together with one computer, in a face-to-face manner. The computer will be mainly accessible by the co-designer, in order to let the co-designer to have the freedom of creativity, the designer will act as a secondary designer.

GUI-ii Screen-Sharing: the designer and co-designer do the interview in distance, however, the co-designer is unable to interact with the software and s/he can only see the screen, so the co-designer constantly gives feedback during the test via Skype and the designer applies the necessary changes according to the co-designer's needs.

GUI-ii Ozlab: Ozlab's primary use is to perform usability test. Ozlab has different view panels for the designer, co-designer and viewers. In the first view panel, which is called "Test Leader", the designers can add, remove, and edit scenes and GUI elements, and also allows co-designers, to freely move GUI elements and the designer can track their mouse movements. Second view panel, which is called "Test Participant", is for the co-designers in order to interact with the system; and the last panel, which is called "Test Viewer(s)", is for possible viewer(s), just in case another person is going to do the analysis, who would like to monitor the test but not to interact with the test. Unlike previous mentioned interview methods, there are two ways to apply this method, one through a laboratory and the other one via an internet-based remote interview method, which we used in an additional experiment in order to compare the remote results with the lab results. The lab should be facilitated with at least two computers, one for the designer and another one for the co-designer, with a microphone and speaker, where the designer can communicate with the co-designer. The interview starts by pressing the start session button from the designer side and finishes by stop session button. The lab may also be facilitated with a dark glassed wall, for the purpose of observing co-designer's behavior. The second way 
of running this interview method, is to do it via internet; though, the designer and co-designer should communicate using a phone call or a massaging app.

Traditional Face-to-Face: in this method, the designers and co-designer sit together face-to-face but with paper and pencil. The co-designer is the main person writing and drawing on the paper, and the designer just cooperates with the co-designer as a secondary designer.

\subsection{Design Phases}

In this research, we applied the four mentioned interview methods, in the following design phases:

Listing interface components: In this phase, the designer prepares a list of interface components to presents it to the co-designer, and starts the interview by an unstructured questionnaire (Preece et al., 2015). Then, the co-designer is asked to edit, delete, combine or add components if necessary.

Sketching: (Rettig, 1994) In this phase, the designer presents the co-designer, with the result of the first phase and asks him/her to review the components list and decide the location/size of them on the interface.

Lo-Fi Prototyping: (Rettig, 1994) In this phase, the co-designer's task is to follow the previous phase's sketch and to replace components with satisfactory GUI elements such as buttons, textboxes, menus, etc.

Hi-Fi Prototyping: (Rettig, 1994) This is the last phase of design, where co-designer choses a convenient way to interact with GUI elements (i.e. if it is best to open a menu by hovering the mouse, or click to open).

\subsection{Comparison Parameters}

In this paper, we selected four parameters to consider while comparing interview methods in each phase:

Duration per component: it is important for designers to know how long an interview method takes. In some design phases, a short and quick interview method may not extract enough information, as it takes time for them to feel comfortable to give feedback for components. On the contrary, in some other phases, it can be cumbersome to use long interview methods, as the co-designer can get exhausted and may start to give insufficient feedback at the end of interview. The reason for considering duration of interview according to the number of components instead of total duration, is that co-designers list different components at the beginning of the design phase, and depends on number of components they list, the total duration of interviews may vary. So, in order to accurately compare interview methods from the time perspective, we need to compare interview duration based on number of components that has been listed at the beginning of design phase.

Willingness to provide information: we asked co-designers to step-by-step elaborate what they are doing and the reason behind their choices. For this purpose, think-aloud method has been used; however, it is not convenient for the co-designer to be reminded to think-aloud while co-designing, as it may put the co-designer in an awkward and uncomfortable situation. By comparing this parameter, we found out which interview method can make the co-designer to speak more willingly. We analyzed each interview's video records and counted the number of words that the co-designer spoke out regarding each component.

Difficulty: in some interview methods, it can take some time for the co-designer to learn how to interact with the interview environment or the related softwares while co-designing. Sometimes this may cause negative effect on the co-designer's willingness to provide information. While the co-designer might need enough time to learn about the interview's environment and related softwares in use, s/he should not go in details while doing a sketch for the first time. This can slow down the interview and may cause longer duration and eventually the co-designer may get bored. This will be measured by the amount of time the co-designer learn how to interact with the environment and asks questions regarding their problems with the interview tools.

Cost: no matter how easy and streightforward an interview method can be, there is always a limited budget for running an interview. Things such as computers, softwares license, renting a lab, etc,

\subsection{Software}

For the purpose of running this interview methods, during some of the mentioned design phases, we have used Pencil and Sketch desktop applications, which are both designing tools with GUI elements available for quick interface designing, corresponding to the design phase. Also, we used Skype, as our messaging app for internet-based remote interview methods since it has a screen-sharing feature and all the co-designers are familiar how to use it. 


\subsection{Test Participants}

There were in total eight participants. All the test participants (co-designers) were university students from various study fields between the age range of 20 to 40, six males and two females. None of them had ever been in a participatory design, and they weren't familiar with the Sketch and Pencil desktop applications or Ozlab web application. Throughout this research paper, we will refer all the test participants as co-designers.

\subsection{Test Leaders}

The test leader is responsible for preparing the unstructured questionnaire, orientation script, non-disclosure agreement (Rubin and Chisnell, 2008) and conducting the literature review and observation. He/she is also responsible for analyzing test results, and act as the Wizard-of-Oz method. Throughout this research paper, we refer the main test leader as designer.

\subsection{The Participatory Design Test}

We have used $4 * 4$ within-subject design experiment, with counterbalancing order (see Table 1 ). It is an approach to iterate the test subjects into all the phases of design without repeating the same interview method.

In Table 1, the first row represents interview methods, and the first column represents design phases. According to counterbalancing order, all the test subjects who are the co-designers, went through all the phases of design one by one. However, in each phase they were interviewed by different methods and no one has repeated the same phase by the same interview method. On the other hand, they received the results from the same interview method. So that, co-designers didn't work on their own results from the previous design phase.

The reason for choosing within-subject design is that the co-designer is already familiar with the previous design phase results, s/he learned how to act in the interview method already familiar with the test goal.

Table $1.2 * 2$ with-in subject design with counterbalancing order

\begin{tabular}{lllll}
\hline Subjects & GUI-ii Face-to-Face & $\begin{array}{l}\text { GUI-ii Screen- } \\
\text { Sharing at Lab }\end{array}$ & $\begin{array}{l}\text { GUI-ii Ozlab at } \\
\text { Lab }\end{array}$ & $\begin{array}{l}\text { Traditional } \\
\text { Face-to-Face }\end{array}$ \\
\hline $\begin{array}{l}\text { Listing Interface } \\
\text { Components }\end{array}$ & $1^{\text {st }}$ Subject & $2^{\text {nd }}$ Subject & $3^{\text {rd }}$ Subject & $4^{\text {th }}$ Subject \\
\hline Sketching & $4^{\text {th }}$ Subject & $1^{\text {st }}$ Subject & $2^{\text {nd }}$ Subject & $3^{\text {rd }}$ Subject \\
\hline Lo-Fi Prototyping & $3^{\text {rd }}$ Subject & $4^{\text {th }}$ Subject & $1^{\text {st }}$ Subject & $2^{\text {nd }}$ Subject \\
\hline Hi-Fi Prototyping & $2^{\text {nd }}$ Subject & $3^{\text {rd }}$ Subject & $4^{\text {th }}$ Subject & $1^{\text {st }}$ Subject \\
\hline
\end{tabular}

For GUI-ii Ozlab remote interview, we used different co-designers group from Stockholm and Uppsala (see Table 2).

Table 2. Order and location of the co-designers for remote GUI-ii Ozlab interview

\begin{tabular}{ll}
\hline Subjects & Remote GUI-ii Ozlab \\
& \\
\hline Listing Interface Component Phase & $5^{\text {th }}$ Subject from Stockholm \\
Sketching Phase & $6^{\text {th }}$ Subject from Uppsala \\
Lo-Fi Prototyping Phase & $7^{\text {th }}$ Subject from Stockholm \\
Hi-Fi Prototyping Phase & $8^{\text {th }}$ Subject Uppsala \\
\hline
\end{tabular}

In remote based GUI-ii Ozlab interview method, we did not follow within-subject design rule. We added remote interview method to compare the lab environments impacts on co-designers' desire to think-aloud.

In order to reduce the mistakes in real test and increase the accuracy, a pilot test (Rubin and Chisnell, 2008) was performed. As a result, we manage to edit the unstructured questionnaire, be more precise while answering their questions and keep the test simple for the co-designers, i.e. using Sketch application for easy learning. 


\subsection{Test Scenario}

In order to run the test, we have decided to perform the participatory design technique on developing an online synchronous learning system user interface from the students' perspective, where the teacher and students meet online at the same time. Though, the goal of the research study is to test the interview methods, not the interface. Same test scenario was used for pilot test but with different participants which all of them were males.

\subsection{Measurement System}

The scales used for the parameters has been categorized as follows: very low, low, below average, average, above average, high, very high. Duration per component range is [0.1,350] (in minutes), willingness to provide information range is [0,900], difficulty range is [0,10], and the cost range is [500\$,15000\$].

\section{RESULT}

This section is divided into two parts, where the first part will display the scaled-based results tables, and the second part will represent charts to compare interview methods based on parameters.

\subsection{Scale-based Tables}

Tables 3,4 and 6 show the result of all the interview video tapes and the screen interactions' analysis. The first row in these tables are the interview methods and the first column to the left are the parameters.

Table 3. Test results from interface components listing phase

\begin{tabular}{llllll}
\hline $\begin{array}{l}\text { Listing Interface } \\
\text { Components }\end{array}$ & $\begin{array}{l}\text { GUI-ii Face-to- } \\
\text { Face }\end{array}$ & $\begin{array}{l}\text { GUI-ii Screen- } \\
\text { Sharing at Lab }\end{array}$ & $\begin{array}{l}\text { GUI-ii Ozlab at } \\
\text { Lab }\end{array}$ & $\begin{array}{l}\text { GUI-ii Ozlab } \\
\text { Remote }\end{array}$ & $\begin{array}{l}\text { Traditional } \\
\text { Face-to-Face }\end{array}$ \\
\hline $\begin{array}{l}\text { Duration Per } \\
\text { Component }\end{array}$ & Low & Below Average & Average & Above Average & High \\
\hline $\begin{array}{l}\text { Willingness to Provide } \\
\text { Information }\end{array}$ & Low & Average & High & Above Average & Below Average \\
\hline Difficulty & Low & Low & Low & Below Average & Low \\
\hline Cost & Average & Above Average & Very High & Low & Below Average \\
\hline
\end{tabular}

In the first phase (see Table 3), considering both duration per component and willingness to provide information, the GUI-ii face-to-face has the lowest outcome as the co-designers always has the false impression the designer fully understand what they do as they look at the same screen, so they don't usually speak-out.

A few difficulties have been reported on GUI-ii Ozlab remote interview method, and it's due to the extra explanations for co-designer to run the Ozlab web application on his/her device. Regarding cost, GUI-ii Ozlab at Usability Lab is the most expensive one, as it requires to rent/own a lab with sophisticated facilities such as dark glassed wall, at least 2 computers, microphones and speakers.

Table 4. Test results from sketching phase

\begin{tabular}{llllll}
\hline Sketching & $\begin{array}{l}\text { GUI-ii Face-to- } \\
\text { Face }\end{array}$ & $\begin{array}{l}\text { GUI-ii Screen- } \\
\text { Sharing at Lab }\end{array}$ & $\begin{array}{l}\text { GUI-ii Ozlab at } \\
\text { Lab }\end{array}$ & $\begin{array}{l}\text { GUI-ii Ozlab } \\
\text { Remote }\end{array}$ & $\begin{array}{l}\text { Traditional } \\
\text { Face-to-Face }\end{array}$ \\
\hline $\begin{array}{l}\text { Duration Per } \\
\text { Component }\end{array}$ & High & Average & Average & Above Average & Very High \\
\hline $\begin{array}{l}\text { Willingness to Provide } \\
\text { Information }\end{array}$ & Low & Average & High & Above Average & Below Average \\
\hline Difficulty & High & Average & Low & Below Average & Low \\
\hline Cost & Average & Above Average & Very High & Low & Below Average \\
\hline
\end{tabular}


In the sketching phase (Table 4), once again GUI-ii Ozlab at Usability Lab has the most satisfactory results by merging both duration per component and willingness to provide information. We also have a huge variation for difficulty parameter; especially on GUI-ii face-to-face: it was twice as difficult as GUI-ii screen-sharing as even though the designer is close by during the face-to-face interview, the co-designer supposed to interact with the system alone and requires some basic understanding about the Pencil desktop application.

One of the advantages of using GUI-ii Ozlab web application is that you cannot have margins for the components on the sketching phase, which help the designers and developers to cover the empty spaces on the web by resizing existing components. On the down-side, using Ozlab web application remotely, causes a slight delay in viewing the co-designer's interactions.

Table 5 differs from other tables presented. First, GUI-ii Ozlab method is not applicable on this phase, which is an advantage as it has interactive GUI elements and easy to rearrange, which helps the designers to combine both Lo-Fi and Hi-Fi prototypes, and instead of doing the design in four different phases, it can be done in three design phases, by avoiding Lo-Fi prototyping phase. However, if a designer is going to use an interview method other than GUI-ii Ozlab for Lo-Fi prototyping phase, it is better to use GUI-ii screen-sharing as it consumes less time and higher willingness to provide information for co-designers. The only disadvantage is that GUI-ii screen-sharing is twice as difficult as GUI-ii face-to-face (Table 4) which has totally the opposite value, by comparing to sketching phase (Table 5); since, in the sketching phase the co-designer only needs to show the location and the size for different components, but for Lo-Fi the co-designer needs to access different GUI elements in the software, which forces them to spend more time on learning during the test.

Table 5. Test results from Lo-Fi prototyping phase

\begin{tabular}{llllll}
\hline Sketching & $\begin{array}{l}\text { GUI-ii } \\
\text { Face-to-Face }\end{array}$ & $\begin{array}{l}\text { GUI-ii Screen- } \\
\text { Sharing at Lab }\end{array}$ & $\begin{array}{l}\text { GUI-ii Ozlab at } \\
\text { Lab }\end{array}$ & $\begin{array}{l}\text { GUI-ii Ozlab } \\
\text { Remote }\end{array}$ & $\begin{array}{l}\text { Traditional } \\
\text { Face-to-Face }\end{array}$ \\
\hline $\begin{array}{l}\text { Duration Per } \\
\text { Component }\end{array}$ & High & Average & - & - & Above Average \\
\hline $\begin{array}{l}\text { Willingness to Provide } \\
\text { Information }\end{array}$ & Low & Average & - & - & Below Average \\
\hline Difficulty & Average & High & - & - & Low \\
\hline Cost & Average & Above Average & - & - & Below Average \\
\hline
\end{tabular}

In Hi-Fi prototyping phase (last phase) (Table 6) GUI-ii screen-sharing interview method is exceptionally difficult as the co-designer cannot interact with the software her/him self, and s/he can only see the shared screen via Skype. Also, they need to learn and remember the GUI elements in order to ask the designer to add it to the screen, it takes longer to accomplish the test.

Table 6. Test results from Hi-Fi prototyping phase

\begin{tabular}{llllll}
\hline Sketching & $\begin{array}{l}\text { GUI-ii } \\
\text { Face-to-Face }\end{array}$ & $\begin{array}{l}\text { GUI-ii Screen- } \\
\text { Sharing at Lab }\end{array}$ & $\begin{array}{l}\text { GUI-ii Ozlab at } \\
\text { Lab }\end{array}$ & $\begin{array}{l}\text { GUI-ii Ozlab } \\
\text { Remote }\end{array}$ & $\begin{array}{l}\text { Traditional } \\
\text { Face-to-Face }\end{array}$ \\
\hline $\begin{array}{l}\text { Duration Per } \\
\text { Component }\end{array}$ & High & Above Average & Average & Average & Very High \\
\hline $\begin{array}{l}\text { Willingness to Provide } \\
\text { Information }\end{array}$ & Low & Average & High & Above Average & Below Average \\
\hline Difficulty & High & Very High & Low & Below Average & Average \\
\hline Cost & Average & Above Average & Very High & Low & Below Average \\
\hline
\end{tabular}

\subsection{Comparison Charts}

Here, we will demonstrate three comparison charts for interview methods. In Figure 1, y-axis represents the number of words that co-designer spoke out regarding each component in 15 minutes time slice, which represents the willingness to provide information. In Figure 2, y-axis is the amount of time co-designer spent to learn about the environment, struggle and/or asks questions regarding their problems with the interview tools on each 15-minute time slice, which represents the difficulty. 


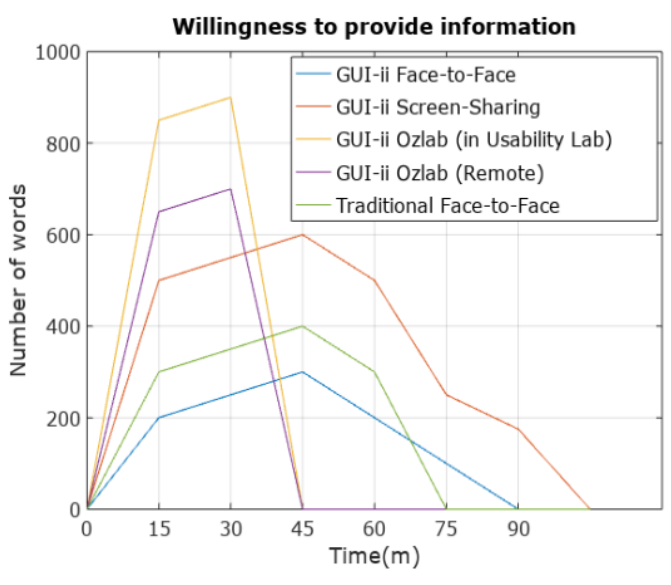

Figure 1. Willingness to talk every 15 minutes

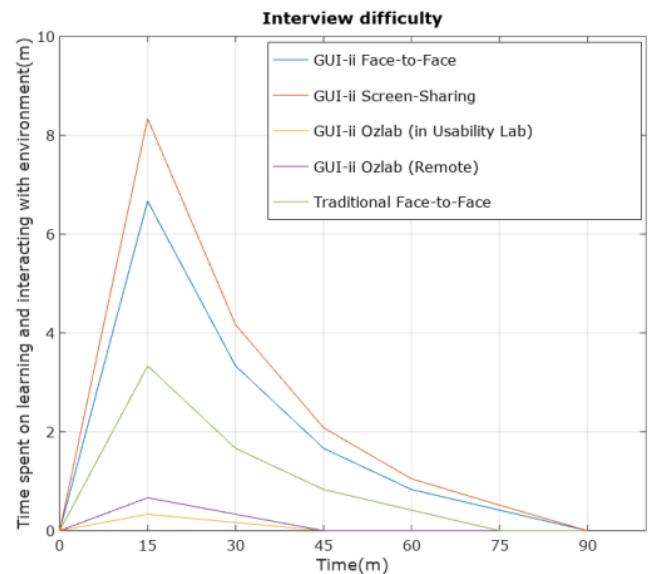

Figure 2. Difficulty every 15 minutes

According to Figure 1, both remote and in-lab approaches in GUI-ii Ozlab interview method has the highest willingness to provide information and it doesn't take long to finish the test. We can also see that if the interview takes longer than one hour, the co-designer lost his/her interest to provide more information as they become tired and exhausted. Furthermore, the sudden drop of "number of words" in GUI-ii Ozlab interview method is because even-though the test is finished but co-designers still had willing to provide us with more information.

The data in Figure 2 demonstrates which interview method is the most difficult to accomplish. As we can see GUI-ii screen-sharing method reached the peak point. Thus, on GUI-ii Ozlab method it is easier for the co-designer to interact with the system without frustration. We can also see it was easier for the co-designers to use the Ozlab web application at the Usability Lab, since the application was ready on the browser while they entered the room. For remote co-designers, there had to gain extra information on how the system works and how you should connect the system via the provided link.

With all the interactive GUI elements available today (such as dropdown menus, accordion menus, etc.) it's hard for co-designers to visually present all kinds of GUI elements on a paper. Hence, they choose to design a primitive GUI and it makes their sketch/prototype misleading.

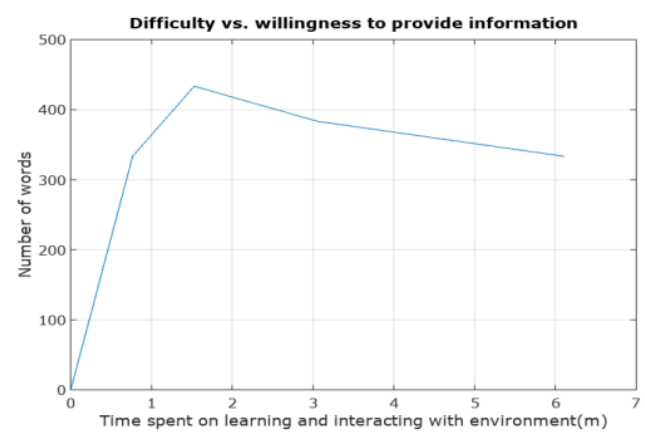

Figure 3. Effect of interview method's difficulty on co-designer's willingness to provide information

In Figure 3, we demonstrated the effect of interview method's difficulty versus co-designer's willingness to provide information. We can observe that when the duration of learning and interacting with the interview environment increases, the number of words the co-designer spoke out decreases. So, we can easily conclude that co-designer's willingness to provide information decreases when interview method's difficulty increase.

\section{CONCLUSION}

We analyzed the effects of three GUI-ii based interview methods as well as traditional face-to-face one, in four different phases of design and also compared the effects of the remote interviews versus lab-based ones. We compared each interview method from different perspective and proposed 4 comparison parameters: duration per component, willingness to provide information, difficulty and cost. 
Besides, we studied the effect of interview method's difficulty on the co-designer's willingness to provide information. We also showed that co-designers tend to provide much more fruitful results when they are in a lab rather than during a remote interview. Moreover, during a face-to-face or a lab-based interview, co-designers were more motivated; either through designing or through think-aloud. However, it is important for the designers to check their available resources (i.e., budget, time and place) before conducting interviews.

This research study provides essential scale-based analysis tables and comparison charts to help future designers make more accurate assumptions when choosing different interview methods for each design phase.

\section{ACKNOWLEDGEMENT}

We would like to thank Prof. John Sören Pettersson, for his support and generosity to let us use the lab facilities. We would also like to say thanks to Fabian Jaskotka and Kai Langenekert for helping out in running the test.

\section{REFERENCES}

Baauw, E., Markopoulous, P., 2004. A comparison of think-aloud and post-task interview for usability testing with children, in: Proceeding of the 2004 Conference on Interaction Design and Children Building a Community - IDC '04. Presented at the Proceeding of the 2004 conference, ACM Press, Maryland, pp. 115-116.

Brush, A.J.B., Ames, M., Davis, J., 2004. A comparison of synchronous remote and local usability studies for an expert interface, in: Extended Abstracts of the 2004 Conference on Human Factors and Computing Systems - CHI '04. Presented at the Extended abstracts of the 2004 conference, ACM Press, Vienna, Austria, p. 1179.

Dimond, J.P., Fiesler, C., DiSalvo, B., Pelc, J., Bruckman, A.S., 2012. Qualitative data collection technologies: a comparison of instant messaging, email, and phone, in: Proceedings of the 17th ACM International Conference on Supporting Group Work - GROUP '12. Presented at the the 17th ACM international conference, ACM Press, Sanibel Island, Florida, USA, p. 277.

Gratch, J., Artstein, R., Lucas, G., Stratou, G., Scherer, S., Nazarian, A., Wood, R., Boberg, J., DeVault, D., Marsella, S., Traum, D., Rizzo, S., Morency, L.-P., 2014. The Distress Analysis Interview Corpus of human and computer interviews, in: Proceedings of the Ninth International Conference on Language Resources and Evaluation (LREC-2014). European Language Resources Association (ELRA), Reykjavik, Iceland.

Nielsen, J., Clemmensen, T., Yssing, C., 2002. Getting access to what goes on in people's heads?: reflections on the think-aloud technique, in: Proceedings of the Second Nordic Conference on Human-Computer Interaction - NordiCHI '02. Presented at the the second Nordic conference, ACM Press, Aarhus, Denmark, p. 101.

Pettersson, J.S., Siponen, J., 2002. Ozlab: a simple demonstration tool for prototyping interactivity, in: Proceedings of the Second Nordic Conference on Human-Computer Interaction - NordiCHI '02. Presented at the the second Nordic conference, ACM Press, Aarhus, Denmark, p. 295.

Pettersson, J.S., Wik, M., Andersson, H., 2018. GUI Interaction Interviews in the Evolving Map of Design Research, in: Paspallis, N., Raspopoulos, M., Barry, C., Lang, M., Linger, H., Schneider, C. (Eds.), Advances in Information Systems Development. Springer International Publishing, Cham, pp. 149-167.

Pettersson, J.S., Wik, M., Andersson, H., 2017. Wizards of Oz in the Evolving Map of Design Research - Trying to Frame GUI Interaction Interviews Supporting Development of Interactive Systems in Interactive Sessions, in: Information Systems Development: Advances in Methods, Tools and Management (ISD2017 Proceedings). Presented at the Information Systems Development: Advances in Methods, Tools and Management (ISD2017), Larnaca, Cyorus.

Preece, J., Rogers, Y., Sharp, H., 2015. Interaction design: beyond human-computer interaction, Fourth edition. ed. Wiley, Chichester.

Rettig, M., 1994. Prototyping for tiny fingers. Commun. ACM 37, 21-27.

Rubin, J.Z., Chisnell, D., 2008. Handbook of usability testing: how to plan, design, and conduct effective tests, 2. ed. ed. Wiley, Indianapolis, Ind.

Simonsen, J., Robertson, T. (Eds.), 2013. Routledge international handbook of participatory design, Routledge international handbooks. Routledge, London.

Spinuzzi, C., 2005. The Methodology of Participatory Design. Soc. Tech. Commun. 52, 163-174.

Steinfeld, A., Jenkins, O.C., Scassellati, B., 2009. The oz of wizard: simulating the human for interaction research, in: Proceedings of the 4th ACM/IEEE International Conference on Human Robot Interaction - HRI '09. Presented at the the 4th ACM/IEEE international conference, ACM Press, La Jolla, California, USA, p. 101. 